\title{
Writing Problems of Non-English Major Undergraduate Students in Bangladesh: An Observation
}

\author{
Shagia Afrin \\ Department of English, Stamford University Bangladesh, Dhaka, Bangladesh \\ Email: shajia.eng@gmail.com
}

Received 3 February 2016; accepted 14 March 2016; published 17 March 2016

Copyright (C) 2016 by author and Scientific Research Publishing Inc.

This work is licensed under the Creative Commons Attribution International License (CC BY).

http://creativecommons.org/licenses/by/4.0/

(c) (i) Open Access

\begin{abstract}
Writing is considered a productive skill and useful tool for learning process. It is the most used skill in evaluating students' performance in almost all levels of education. In Bangladesh, tertiary level students still face enormous writing problems in English. The present study aims to explore writing problems of non-English major undergraduate students at a private university in Bangladesh. The study was conducted on 89 non-English major undergraduate students from different departments studying at Stamford University Bangladesh. The data were taken through document collection and questionnaire. Moreover, a semi-structured interview on twelve teachers has been conducted to reflect their attitudes and opinion on students' English writing problems. In addition, a few recommendations are provided on the basis of the result. This study could help the teachers to resolve the problems and find some strategies to improve students' writing in English.
\end{abstract}

\section{Keywords}

Writing Problems, Non-English Major, Undergraduates, Private University

\section{Introduction}

In communicative language teaching, writing is one of the four basic language skills, and it holds a major part of learning a language because students are to sit for examination to prove their competence by writing properly. In our country, English is taught as a compulsory subject from primary level to higher secondary level. Even the English language has been adopted as a medium of instruction in all private universities because English has become "the medium of a great deal of the world's knowledge" [1]. Nonetheless, the frustrating news that most 
of the students at the tertiary level, especially in the private university are very weak in the writing skills. After completing their secondary and higher secondary level, they fail to show their expected competency. In this regard, Hoque [2] notes, "Despite the considerable amount of time devoted to English instruction, the general proficiency and achievement of the majority of the students graduating from high schools is unsatisfactory and disproportionately low."

In Bangladesh, many private universities offer different English language courses along with the core courses in various departments to teach writing as a skill, and the objective of these courses is to sharper learners' language skills for academic, professional or personal purposes. However, the outcome is not satisfactory. The proficiency level of English among students is very low due to their educational background. Most of the students come from Bengali medium, and they are not able to write effectively. That's why it is more challenging teaching writing skills in English language, especially whose English language course is non-major. The fact is that non-major students always busy and keep thinking of their core courses. They just want to get average marks in English course. It shows their lack of interest in English that impedance their academic progress. They are not motivated, and feel burdened in the English language classroom. They also feel daunted by the classroom activities. That's why writing skills to non-English major students is really problematic.

This study aims to find out the writing problems of non-English major undergraduate students at a private university in Bangladesh. The study is also intended to share some recommendations how students can get overcome those problems.

\section{Literature Review}

Writing skills are an important part of communication for our students throughout their academic life because it allows them to organize their feelings and ideas clearly as well as to convey meaning through well-constructed text. David Nunan [3] defines:

Writing is both a physical and mental act. At the most basic level, writing is the physical act of committing words or ideas to some medium. On the other hand, writing is the mental work of inventing ideas, thinking about how to express them, and organizing them into statements and paragraphs that will be clear to a reader.

In the recent years or more, there has been a growing concern in developing writing skills in the higher education as education diversifies at this stage. Learners go on to more specific knowledge acquiring situation where their writing has to more focused and specific oriented [4]. According to Bjork and Raisanen: We highlight the importance of writing in all university curricula not only because of its immediate practical application, i.e. as an isolated skill or ability, but because we believe that, seen from a broader perspective, writing is a thinking tool. It is a tool for language development, for critical thinking and, extension, for learning in all disciplines [5].

It is mentioned earlier in Bangladesh English is taught compulsorily in all levels of education. Khan and Akter [2] note in their study:

In our teaching-learning context, writing skill is usually considered as a clear proof of whether learners learnt English well or not. Learners sit for different examinations and get grades/scores on the basis of writing ability. Although other three skills are more or less practiced in the class, only writing ability is assessed for grades or scores in the examination.

University students must be able to write clearly about topics related to their research fields [6]. Even after practicing writing for a long time students face numerous writing problems when they join university for higher education. Uddin [7] writes in his study, "Writing is the most focused but the least developed English language skill among the learners in Bangladesh. At tertiary level the situation is not different". It is an assertion that the importance of writing is not unique to liberal arts or social sciences alone but is also germane in science and technology courses [8]. Dudley-Evans and St. John [5] states that success in the relevant fields depends on the factor that how effectively the students handle different writing genres like summaries, essays, reviews, etc. This is applicable to the students of all disciplines in English-major and non-major students in particular.

Students may face many problems in their English writing as L2 writers. In this regard, Alam mentioned, "It is often found that students may have knowledge about vocabulary and grammatical aspects (e.g. using the right tenses, collocation, and prepositions) but face problems in writing coherently and re-structuring ideas after evaluating them" [6].

According to Heaton [9]: The writing skill in a foreign language is complex and difficult to learn not only the 
ability to use structures, but also conceptual of varied skills such as stylistic and mechanical skill. Stylistic skill is the ability to manipulate sentences and use language effectively whereas mechanical skill is the ability to use correctly those conventions peculiar to the written language such as punctuation and spelling.

A growing mass of research has offered valuable insights into the significance of this skill for academic success. In Bangladesh many researchers have studied on students' writing problems. In their research, Khan and Akter [2] identified undergraduate students' word and sentences level mistakes in English writing. In this regard, they suggested,

"In the training curriculum, aims and objectives should be appropriately designed and utilized to make sure it is effectively linking the praxis of writing which is inevitably essential in today's English teaching and learning context."

Ahmed [10] found in his study that Bangladeshi students are seriously prone to making mistakes in English articles. He pointed out that mistakes occurred because of the differences between Bangla and English language.

In her study, Mustaque. S. [6] reveals undergraduate students’ writing samples exhibit innumerable errors, i.e. lexio-semantic errors, errors with verbs, prepositions, articles. She illustrates that the participants write without any planning, purposeless.

In another study by Fahmida, B. [11] identifies Bangladeshi tertiary level students' common errors in their academic essay. Different types of errors are spelling, punctuation and organizational problems. She recommends that more intensive English courses should be there before they take their major course of their respected area.

Various studies have been carried out focusing on error analysis of ESL learners in different language and culture contexts. Seyabi and Tuzlukova [12] investigate the gaps in English language teaching and learning that exist between post-basic schools and universities in the Sultanate of Oman. They also identify that, "Majority of students, representing both educational contexts struggle with lexical and content aspects of writing; however, university students' perceptions of the kind of problems they encounter and of the strategies to address them are more assertive."

After doing research on Chinese students Darus and Ching [13] showed that the four most common errors made by the Chinese students are the mechanics of writing, tenses, prepositions, and subject-verb agreement. Another research of Javed and Umer [14] revealed that students have serious problems in their academic writing due to their weaknesses in using appropriate lexical items, organization of ideas and grammar. The other weaker areas are prepositions, spellings, irregular verbs, articles, punctuation, suffixes and prefixes.

Therefore, we can see that many researchers have found that writing in a second language poses many problems for the majority of English as a foreign language (EFL) learner. In Bangladesh undergraduate students have still an alarming tendency to make mistakes in syntactical and lexical level. Many Researchers have also offered valuable insights into the approaches of teaching writing skills.

\section{Research Methodology}

\subsection{Participants}

All the participants in this study are non-English major undergraduate students from the different departments of a private university, namely Stamford University Bangladesh. Non-English major private university students are chosen because the medium of instruction at all the private universities is solely English and private universities are expected to bring about a big positive change in students four basic language skills. Total 89 non-English major students were randomly selected who had already completed English fundamentals (100) and English composition (101) course. These courses are for students who require more language practices having a good command over the English Language. The objective of these courses is to build up the students writing ability in English in a formally correct way and to achieve some grammatical proficiency needed for both reading and writing. Among 89 students, 12 students are from Microbiology (MBO), 8 from Film and Media studies (FMS), 20 from Pharmacy (BPH), 25 from Business Administration (BBA), and 24 from Computer Science (CSE) in Stamford University Bangladesh. Among them, 68 students are male, 21 students are female. The age of the students ranges 20 - 23 years. These learners have already finished their secondary and higher secondary level where English was a compulsory subject. On the other hand, the researchers also provided a questionnaire of eleven close-ended statements to the selected students from the same Institute to elicit their responses. A 
semi-structured interview is taken as well from twelve (12) teachers who are currently teaching above mentioned non-English major courses in different departments. As regards the teachers, all are highly experienced teacher from different private universities, including Stamford University Bangladesh, East West University, American International University Bangladesh, and International University of Business Agriculture and Technology. Among them, 10 are lecturers and 2 are senior lecturers. Both boy and girl students; male and female teachers have been selected randomly, so that respondents cover both gender groups and better findings can be facilitated as well.

\subsection{Data Collection}

Data were collected through writing sample analysis, questionnaire and interviews.

\subsubsection{Writing Samples}

As instruments the researcher used to collect data from writing samples of the participants and questionnaires. Writing samples (see Appendix B) were chosen as a research instrument to get a clear picture about the writing problems of the non-English major students. For collecting data, two descriptive topics were given in a time pressure of forty-five minutes. The participants were assured that their writing samples won't be counted in exam, and it's just a writing activity. This made the participants feel free and comfortable in writing a paragraph. The participants were informed that they had to start with prewriting then a final draft. The students did not know that their writings are going to be under investigation. In the first topic, students were asked to write a descriptive paragraph about Phohela Baishak (The first day of Bangla New Year), and the second topic students were asked to write about Ekushe Book Fair (Book Fair of the immortals of the 21st [of February]). The students were asked to write freely and to express their ideas clearly about those topics. The writing samples presented a vivid picture about the students' composing \& writing problems. As all the participants were the direct students of the researcher, she managed to collect writing samples and questionnaire in her scheduled class time.

\subsubsection{Questionnaire}

Another research instrument used by the researcher to collect data was a written questionnaire (see Appendix A) which included eleven close ended questions with fixed alternatives covering the research questions as well as subject related. The questionnaire was delivered to each of the eighty-nine students. Each student completed and returned the questionnaire. While filling up the questionnaire, students were asked that writing their name was not mandatory, it is optional. The questions in the questionnaire were set to obtain information about their attitude, problems, opinions and motivations as a non-major English student. These questions were designed to gather information about the problems which they are facing while writing and their way of dealing with them. The result of the survey conducted among the participants was counted into percentage. From the responses of the participants the researcher finds out the reasons of their writing problems.

\subsubsection{Interviews}

Twelve teachers who were offering courses to first year undergraduate students \& currently teaching were interviewed to find out their perceptions of the non-English major undergraduate students' writing problems. Each interview lasted about ten minutes. The interviews were audio taped and then transcribed by the researchers.

\section{Findings and Discussion}

\subsection{Findings from Writing Samples}

The results of this study showed that students face many problems when writing English. It is an undeniable fact that an understanding of a language grammar is essential, and as it is said vocabulary is the flesh of the language and grammar is the skeleton. An analysis of the students' paragraphs revealed that various kinds of mistakes made students writing weak. Sentence levels grammatical mistakes committed by the students, namely spelling, subject-verb agreement, articles, preposition, capitalization, fragments, punctuation, tense, etc. they have also problems with paragraph structure, coherence and cohesion, etc. By examining the writing samples of the students, it can be presumed that a significant number of the students that is $90 \%$ cannot organize their ideas. While writing they show more concern for language related problems. 


\subsubsection{Category of Writing Problems}

Table 1 gives a statistical summary of the main writing problems noted from the students' writing samples arranged on the basis of raw frequency rank order starting with the highest to the lowest frequencies (Figure 1).

1) Spelling Mistakes

As can be seen from Table 1, the spelling mistakes are the most common writing problem noted throughout this study 489 (23.04\%). It ranks number one out of eleven. Students have a tendency to spell words according to their pronunciations. They commit spelling errors of letter omission, addition, transposition and substitution, etc. For example, attactive (attractive), togetheir (together), favoriet (favorite), famas (famous), etc. Presumably a lot of spelling mistakes occurred because of L1 interference. Actually, in Bangla language students usually learn to spell words, according to orthographically rather than phonetically. That's the main reason to spell wrong words in English.

\section{Table 1. Classification of writing problems and percentage per category.}

\begin{tabular}{cccc}
\hline No & Category of writing problems & Frequencies of writing problems & Percentage (\%) \\
\hline 1 & Spelling & 489 & 23.04 \\
2 & Tense & 396 & 18.66 \\
3 & Subject-verb agreement & 305 & 14.37 \\
4 & Punctuation & 218 & 10.27 \\
5 & Fragment & 131 & 6.17 \\
6 & Preposition & 129 & 6.07 \\
7 & Number & 104 & 4.90 \\
8 & Pronoun & 98 & 4.61 \\
9 & Misuse of words/wordiness & 89 & 4.19 \\
11 & Articles & 87 & 4.09 \\
\hline
\end{tabular}

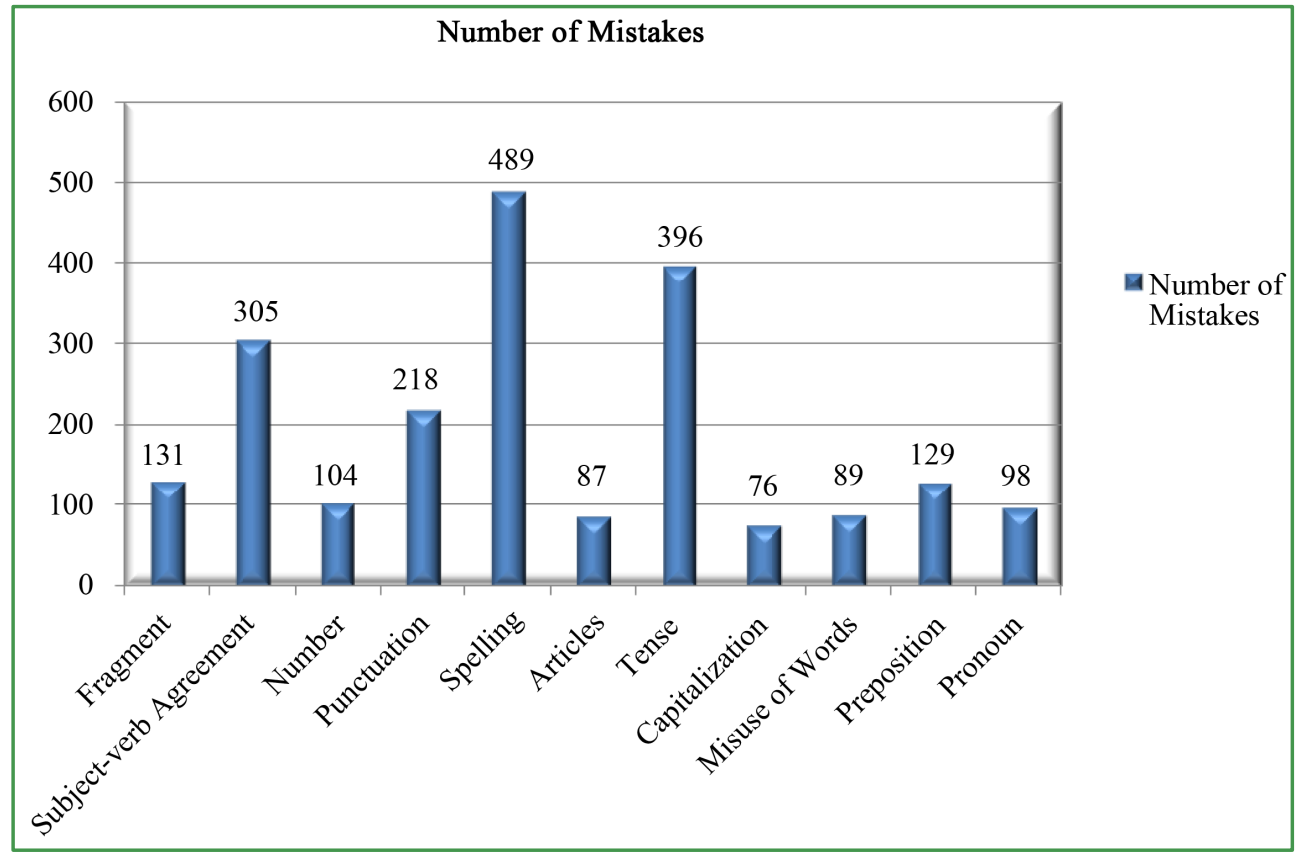

Figure 1. Total number of mistakes. 


\section{2) Misuse of Tense}

The second most common problem faced by students is the misuse of tense of their writing 396 (18.66\%). They are unaware about mixing both present and past tense in the same paragraph or sentence. On the other hand, English does have numerous possible tenses (verb forms), and their uses are not always helpful to the learner. The past simple tense, for example, can be used to talk about the future: If I had a wing, I would fly in the sky. So Many students get confused which tense (verb form) is required to express clearly the meaning that they wish to convey, e.g. from my heart, I told that I like the Pohela Boishakh very much (I want to say that I like the Pohela Boishakh very much).

3) Subject-Verb Agreement

Students have always been taught to use a verb which should agree with its subject. In spite of that, many errors were made in this area 305 (14.37\%). They use a plural verb with singular subject and vice-versa, e.g. In Phohela Baoishak females wears shari and males wears pajama and punjabi (In Phohela Baoishak females wear shari and males wear pajama and panjabi).

4) Punctuation \& Fragments

Some students made fragments when they wanted to write complex sentences. Because of wrong punctuation, so many sentence fragments, comma splice and run-on sentences were found. Sometimes their long sentences became over-loaded sentence without proper punctuation. Punctuation mistakes were made by students which constitute 218 (10.27\%), and mistakes made with fragments were 131 (6.17\%).

5) Preposition

Most of the students were found to use an unnecessary preposition in their writing 129 (6.07\%). In some cases, they added inappropriate preposition, e.g. Many publishers of Bangladesh participate from fair with their book stall (many publishers of Bangladesh participate in fair with their book stall).

6) Number

The total mistakes made with regard to the number were 104 (4.90\%) which proof that undergraduates students' still had difficulty in understanding the concepts of the singular and plural number in their writing, e.g. Much books are selling in Ekushey Book Fair (Many books are selling at Ekushey Book Fair).

7) Pronoun

The number of mistakes related to the right use of pronoun agreement and references 98 (4.61\%), e.g. Each person enjoy their moment in the book fair (Each person enjoys his or her moment in the book fair).

8) Misuse of words \& word choice

Students had mother tongue interference in their writing. They often misuse translation from Bangla to English, e.g. We eat ellish fish, pantabat and aluvorta in this day. We can see alpona in roads... They also make errors in the choice of the suitable words or phrases that add nothing to the meaning. The total mistakes that occurred in relation to misuse of words \& word choices were 89 (4.19\%).

9) Misuse of articles

Undergraduate students still had difficulty in understanding the concepts of definiteness and indefiniteness. Some students had a tendency to use "the" where it is not necessary. In some cases, our students over-corrected themselves by using articles hastily. The number of total mistakes made with regard to article was 87 (4.09\%).

10)Capitalization

The number of mistakes related to capitalization 76 (3.58\%), especially pronoun I \& writing a letter as an uppercase and others as a lower case based on specific rules, e.g. when i meet the writer jafariqbal in the ekushaey fair... (when I meet the writer Jafar Iqbal in the Ekushaey Fair...).

\subsubsection{Organizational Problems}

When we talk about effective writing, we often think first about elements like word choice, grammar and mechanics, and content or evidence. However, a really important part of effective writing is logical organization. The researcher analyzed the problems from the content of the paragraph writing. At first, the students were asked to write a descriptive paragraph. Most of them did not follow a beginning, middle, and an end. Students failed to write an effective topic sentence, supporting details and concluding line. These samples create the impression that the participants fail to form any clear idea about their writing topic. They fail to generate ideas and lack appropriate information. Lack of structure, unity and irrelevant ideas were found in their writings. Both paragraphs were lack of transitional phrases. The majority of the students had limited vocabulary and struggled to express their ideas. Plagiarism was a serious writing problem among most of the students. Repetition was 
another problem. It is evident that that students struggling when they write in English. They never bother to plan their composition and all they think just to pass exam which lead to poor and ineffective writing at the end. Only a few students able to organize ideas coherently, fulfilled the required word limit, fewer errors, and seldom include any irrelevant ideas.

\subsection{Findings from a Questionnaire}

Table 2 shows the questionnaire administered to the students and the number of respondents per each degree of response. The majority of students do not have sufficient command over the necessary sentence structures for writing in English (88\%). They do not feel confident to express their ideas in writing (74\%); they cannot write on any relevant topic easily (77\%). The majority of the students do not use prewriting techniques (63\%). They do not practice in home for writing (91\%); however, they like the courses in which they are taught writing English (70\%). They are encouraged by the teachers to practice writing in English in the classroom (92\%); nonetheless, they are not motivated in non-English major Classes (70\%). Students are not more concern about grammar rather than organization patterns of writing (66\%). Some students reveal that they like the English language courses for developing their skill (69\%); however, the majority of the students think their English is not better now than it was at the college (70\%).

On the other hand, a few students use prewriting techniques (37\%), they can write easily on any relevant topic easily (23\%). A few students practice at home for writing (9\%). They do not like the courses in which they are taught writing English (30\%). The minority reveals that they do feel confident to express their ideas in writing (26\%); they have sufficient command over the necessary sentence structures for writing in English (12\%). Some

Table 2. Summary of findings from a questionnaire.

\begin{tabular}{|c|c|c|c|}
\hline Questions Topic & Answer Type & Number of students & Percentage (\%) \\
\hline \multirow{2}{*}{$\begin{array}{l}\text { 1. Do you have sufficient command over the necessary sentence } \\
\text { structures for writing in English? }\end{array}$} & Yes & 11 & 12 \\
\hline & No & 78 & 88 \\
\hline \multirow{2}{*}{$\begin{array}{l}\text { 2. Are you more concern about your grammar rather organization } \\
\text { pattern of writing? }\end{array}$} & Yes & 59 & 66 \\
\hline & No & 30 & 34 \\
\hline \multirow{2}{*}{ 3. Can you easily write on any relevant topic? } & Yes & 20 & 23 \\
\hline & No & 69 & 77 \\
\hline \multirow{2}{*}{ 4. Do you use prewriting techniques? } & Yes & 33 & 37 \\
\hline & No & 56 & 63 \\
\hline \multirow{2}{*}{ 5. Do you practice at home for writing? } & Yes & 8 & 9 \\
\hline & No & 81 & 91 \\
\hline \multirow{2}{*}{$\begin{array}{l}\text { 6. Do you feel confident in your ability to express your ideas in } \\
\text { writing? }\end{array}$} & Yes & 23 & 26 \\
\hline & No & 66 & 74 \\
\hline \multirow{2}{*}{ 7. Do you feel motivated in your non-major English classes? } & Yes & 27 & 30 \\
\hline & No & 62 & 70 \\
\hline \multirow{2}{*}{$\begin{array}{l}\text { 8. Do you like the English languages courses for developing your } \\
\text { writing skill? }\end{array}$} & Yes & 61 & 69 \\
\hline & No & 28 & 31 \\
\hline \multirow{2}{*}{$\begin{array}{l}\text { 9. Do you like the way in which you are taught English writing } \\
\text { skill? }\end{array}$} & Yes & 62 & 70 \\
\hline & No & 27 & 30 \\
\hline \multirow{2}{*}{$\begin{array}{l}\text { 10. Do your teachers encourage you to practice writing in English } \\
\text { in the classroom? }\end{array}$} & Yes & 82 & 92 \\
\hline & No & 7 & 8 \\
\hline \multirow{2}{*}{$\begin{array}{l}\text { 11. Do you think your English now better than it was at the } \\
\text { college? }\end{array}$} & Yes & 27 & 30 \\
\hline & No & 62 & 70 \\
\hline
\end{tabular}


students do not like the English language courses for developing their skill (31\%). A few students are encouraged by teachers to practice writing in English in the classroom (8\%) and motivated in the English language classroom (30\%). Some students are (34\%) more concern about the organizational patterns of writing rather than grammar and think their English is now better than it was at the college (30\%).

\subsection{Findings from Interviews}

The responses of the interviewees were counted into percentage after conducting the semi-structured interviews. The assorted responses from interviews with ten lecturers and two senior lecturers tended to agree in many ways.

1) All the interviewees in this study mentioned that grammatical weakness was the main problem of the non-English major undergraduate students.

2) Lack of vocabulary and motivation are the reasons behind the weakness in English writing skill. Students do not participate in the classroom. They are just mute spectators and do not reveal their writing problems. Sometimes students do not ask for the teacher any kind of clarification or solution.

3) Another problem was knowledge and understanding. Students do not know the process of writing and how to write a topic. Overall, they do not know how to develop supporting details. One teacher said, "When I ask students to write any topic, they take it lightly. They just gather irrelevant ideas carelessly and hastily. They cannot concentrate to express ideas clearly. They think that this writing piece won't be counted for grades.”

4) Teachers believe that almost most of the students never write outside the classroom even for assigned assignments. That is the major problem for students because this practice makes them becoming a weaker writer. They just write in the classroom and exam hall. Another teacher said, "it's true that most of the students always try to avoid writing into the classroom. They request to give an assignment or homework, but we should make them practice the given topic in the class room. This will help a lot.”

5) Teachers believe that students' educational background plays a major role of their weakness of writing. In Bangladesh majority students are from Bangla medium and curriculum designs are exam oriented. That is why they feel comfortable with Bangla writing.

6) Memorization is only one tool to get good grades for Bengali medium students which hampers their English writing capabilities.

7) All the interviewees, $90 \%$ acknowledged that their emphasis had been on semester course content coverage and presentations. They also expressed because of time limitation it becomes difficult to attend to individual writing problems.

8) Seven teachers (58\%) blamed a semester/trimester system as placing undue pressure on the students.

9) Ten teachers (83\%) blamed that students are more concerned about their major course, and one of the most common allegations from students is that they do not have much time for studying their non-English major course and always show excuses for not improving their writing skill. They used to find out how to manage to get a medium grade for an English course. Thus, make them becoming a weak writer and do not feel comfortable with their study at an English medium university.

\section{Limitations of the Study}

The research was conducted on a small group where eighty-nine students took part in the investigation process, and they were all private university students and from the same Institute. If one more private university in the city were covered, it could provide more solid information. Another limitation of the study is that the students' data is collected through questionnaire and the writing samples. Through the questionnaire, the findings reflect mere opinions of students about their problems in writing. Interview of the students could have been more helpful to collect appropriate data. The findings of this study do not have the required authenticity to be generalizable. Another demerit of the study was that we just found out teachers' opinions about causes of students writing problems. However, the study does not reflect what teachers do in the classroom based on these problems. So, further extensive research through classroom observation is required to validate the outcomes of this study.

\section{Recommendations}

It is not very easy to draw general recommendations based on the findings of this study that investigated a small 
group of participants; however, relevant solution or suggestion may support to some extent.

- The findings suggest that the numbers of English language courses that are offered for non-departments as well as the opportunities of writing practice in the classrooms are not sufficient. It is strongly recommended that the language courses should be increased for non-English departments to strengthen all the language skills in general especially in writing.

- In fact, the students who are taught writing in the traditional way do not know how to write standard paragraphs and essays. The way they practice writing in their academic setting, make them to focus on the finished written product rather than the writing process. Many undergraduate students are still weak in Bangla writing let alone in writing English because they are not taught how to write academically even in their first language (Bangla). If these students are taught the basics and strategies of writing in general, they will learn to write in the exam as well as acquire the ability to produce coherent writing on any topic.

- Actually, the traditional teaching method is a major cause for students' weak writing, and it is strongly recommended that the English faculty members who take classes in non-departments should exploit modern teaching techniques. At the same time, teachers should provide their students with as many opportunities to practice the target language as possible. No doubt good writing depends on the mastery of the grammar of the target language.

- To enrich vocabulary, learners should spend some amount of their time based on their limitations. They should follow a good ESL learners' English to English Dictionary such as Oxford Advanced Learner's Dictionary to look up the meaning of unknown and difficult words. In addition, they should maintain a diary to note down the usage of these words.

- Adequate teaching aids and modern equipment should be provided in university to motivate the students to use English with the teachers.

- Motivation and attitude are not only related to the learners, but to the teacher him/herself. Curriculum design should be revised for non-departments students. The questions set for the exams should be creative, not repetitive. Improving writing problems should be treated as a long-term job.

- Feedback is intended to help our students improve their own writing. The weak students should be divided into small groups and put under the supervision of the teachers for the whole period of their study at the university. It is always helpful to encourage students to use different activities and strategies to improve their writing, e.g. keep a journal, poster presentation, use a word processor, etc. The English teachers need to spend a great deal of time checking, marking and giving feedback to their students.

\section{Conclusion}

The study has tried to identify major writing problems of non-English major undergraduate students at a private university in Bangladesh. It has been also found that grammatical weakness, less practice, lack of motivation and educational background were the main reasons behind the weakness of non-English major students. To overcome those problems, students need the proper guidelines, and at the same time students have to find out their own writing problems to become a good writer. The curriculum should pay more attention to learners' needs as well. It is useful to raise the learners' confidence, and to do that the task of developing English language, especially writing skills cannot be done by the English course teachers alone. All other course teachers should share the work.

\section{References}

[1] Crystal, D. (2003) English as a Global Language. 2nd Edition, The Press Syndicate of the University of Cambridge, Cambridge, 110. http://dx.doi.org/10.1017/CBO9780511486999

[2] Khan, H.R. and Akter, M.Z. (2011) Students’ Mistakes and Errors in English Writing: Implications for Pedagogy. 8, 11, 23. http://www.ewubd.edu/ewu/downloadfile/crt/Research\%20Report\%20No.1\%202011.pdf

[3] Nunan, D. (2003) Practical English Language Teaching. International Edition, McGraw-Hill, Singapore, 88.

[4] Rahman, M. (2009) Approaches to Teaching Writing in Higher Education: An Enquiry from the Applied Linguistics Point of View. Stamford Journal of English, 5, 166-167.

[5] Khairy, M.A. (2013) Saudi English-Major Undergraduates’ Academic Writing Problems: A Taif University Perspective. English Language Teaching, 6, 1-2. http://dx.doi.org/10.5539/elt.v6n6p1

[6] Mustaque, S. (2014) Writing Problems among the Tertiary Level Students in Bangladesh: A Study in Chittagong Re- 
gion. Language in India, 14, 334. http://www.languageinindia.com/jan2014/shakiladissertation.html

[7] Uddin, M.E. (2014) Teachers' Pedagogical Belief and its Reflection on the Practice in Teaching Writing in EFL Tertiary Context in Bangladesh. Journal of Education and Practice, 5, 116.

[8] Bodunde, H.A. and Sotiloye, B.S. (2013) A Critique of Undergraduate Students' Writing Skill in an ESL Setting: Samples from the Federal University of Agriculture, Abeokuta, Nigeria. World Journal of English Language, 3, 10. http://dx.doi.org/10.5430/wjel.v3n2p10

[9] Heaton, J.B. (1979) Writing English Language Tests: A Practical Guide for Teachers of English. 5th Edition, Longman, London, 138.

[10] Ahmed, S. (1999) The Problem of Teaching English Grammar to Bengali-Speaking Students. Collected Papers, The British Council and the NCTB, Dhaka.

[11] Fahmida, B. (2010) Bangladeshi Tertiary Students’ Common Errors in Academic Writings. http://dspace.bracu.ac.bd/handle/10361/252

[12] Seyabi, F.A. and Tuzlukova, V. (2014) Writing Problems and Strategies: An Investigative Study in the Omani School and University Context. Asian Journal of Social Sciences \& Humanities, 3, 34. http://www.ajssh.leena-luna.co.jp/AJSSHPDFs/Vol.3(4)/AJSSH2014(3.4-05).pdf

[13] Darus, S. and Ching, K.H. (2009) Common Errors in Written English Essays of Form One Chinese Students: A Case Study. European Journal of Social Sciences, 10. http://www.academia.edu/368278/Common Errors in Written English Essays of Form One Chinese Students A Case_Study

[14] Javid, C.Z. and Umer, M. (2014) Saudi EFL Learners’ Writing Problems: A Move Towards Solution. http://worldconferences.net/proceedings/gse2014/toc/papers_gse2014/G\%20078\%20-\%20CHOUNDHARY\%20ZAHI D\%20JAVID_Saudi\%20EFL\%20Learners_\%20Writing\%20Problems\%20A\%20Move\%20towards\%20Solution_read. pdf 


\section{Appendix A}

\section{Survey Questionnaire}

This questionnaire is designed to conduct a research on "Writing Problems of Non-English Major Undergraduate Students in Bangladesh: An Observation”.

The major objective of this research is to explore writing problems of non-English major undergraduate students at a private university in Bangladesh. Please complete the following questions to reflect your opinion as accurately as possible. Please put a tick mark on your answer. The date collected through this survey will be kept strictly confidential and will be sued for the academic research only.

Thank you very much for your time and opinion.

\section{Demographic Information}

Name of the Participant:

Name of the Institute and Department:

Semester/Trimester:

Age:

\section{Questionnaire}

1) Do you have sufficient command over the necessary sentence structures for writing in English? $\mathrm{Y} / \mathrm{N}$

2) Are you more concern about your grammar rather organization pattern of writing? Y/N

3) Can you easily write on any relevant topic easily? Y/N

4) Do you use prewriting techniques? $\mathrm{Y} / \mathrm{N}$

5) Do you practice at home for writing? Y/N

6) Do you feel confident in your ability to express your ideas in writing? $\mathrm{Y} / \mathrm{N}$

7) Do you feel motivated in your non-major English classes? Y/N

8) Do you like the English languages courses for developing your writing skill? Y/N

9) Do you like the way in which you are taught English writing skill? Y/N

10)Do your teachers encourage you to practice writing in English in the classroom? $Y / N$

11)Do you think your English now better than it was at the college? $\mathrm{Y} / \mathrm{N}$ 


\section{Appendix B}

\section{Writing Samples}
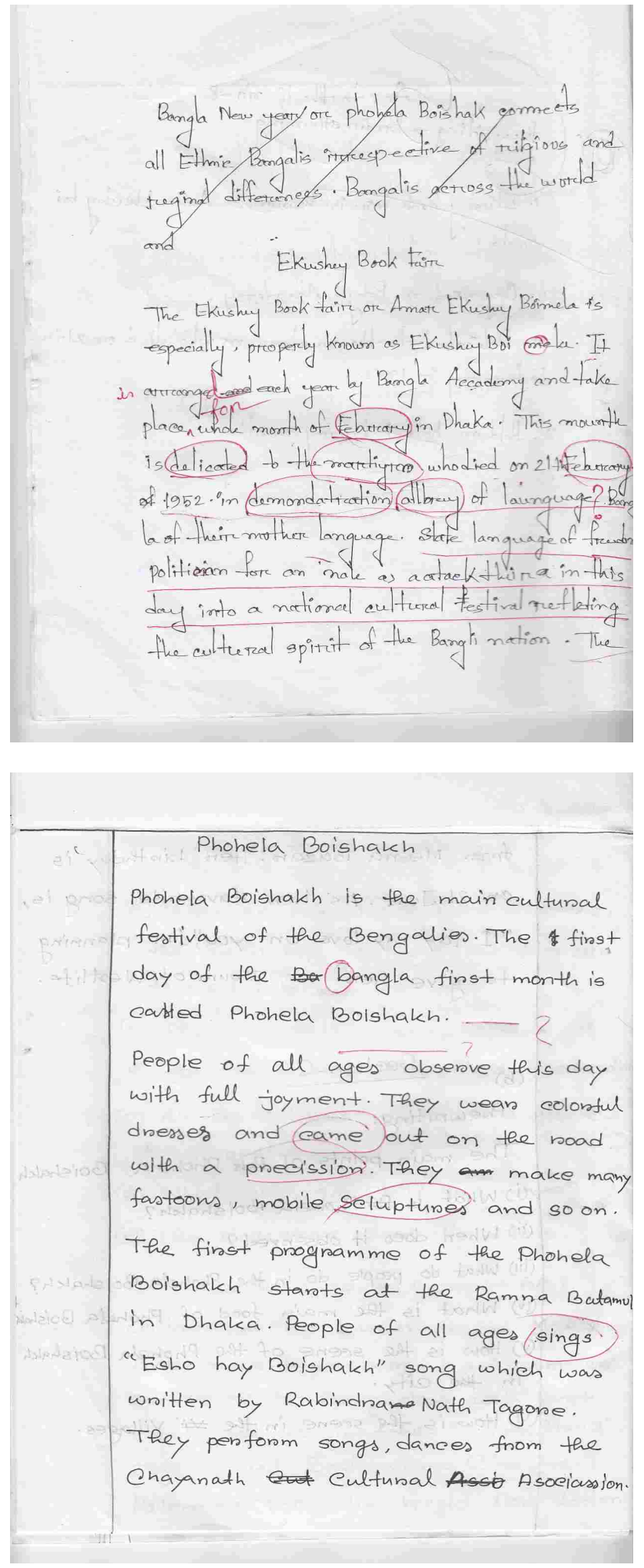